\title{
Effect of dampness at home in childhood on bronchial hyperreactivity in adolescence
}

\author{
T Nicolai, S Illi, E von Mutius
}

\begin{abstract}
Background-Relatively little is known about risk factors for the persistence of asthma and respiratory symptoms from childhood into adolescence, and few studies have included objective measurements to assess outcomes and exposure.

Methods-From a large cross sectional study of all 4th grade school children in Munich (mean age 10.2 years), 234 children $(5 \%)$ with active asthma were identified. Of these, $155(66 \%)$ were reinvestigated with lung function measurements and bronchial provocation three years later (mean age 13.5 years).
\end{abstract}

Results-At follow up $35.5 \%$ still had active asthma. Risk factors for persisting asthma symptoms in adolescence were more severe asthma (OR 4.94; CI 1.65 to 14.76; $p=$ 0.004) or allergic triggers (OR 3.54; CI 1.41 to 8.92; $p=0.007$ ) in childhood. Dampness was associated with increased night time wheeze and shortness of breath but not with persisting asthma. Risk factors for bronchial hyperreactivity in adolescence were bronchial hyperreactivity in childhood ( $p=0.004)$, symptoms triggered by allergen exposure (OR 5.47; CI 1.91 to $25.20 ; p=0.029$ ), and damp housing conditions (OR 16.14; CI 3.53 to 73.73 ; $p<0.001$ ). In a subgroup in whom house dust mite antigen levels in the bed were measured ( $70 \%$ of the sample), higher mite antigen levels were associated with bronchial hyperreactivity (OR per quartile of mite antigen 2.30; CI 1.03 to $5.12 ; p=0.042$ ). Mite antigen levels were also significantly correlated with dampness $(p=0.05)$. However, the effect of dampness on bronchial hyperreactivity remained significant when adjusting for mite allergen levels (OR 5.77; CI 1.17 to $28.44 ; p=0.031$ ).

Conclusion-Dampness at home is a significant risk factor for the persistence of bronchial hyperreactivity and respiratory symptoms in children with asthma. This risk is only partly explained by exposure to house dust mite antigen.

(Thorax 1998;53:1035-1040)

Keywords: asthma; adolescence; dampness

The increasing prevalence of asthma and allergies in children in many countries has prompted investigations into the possible pathogenetic role of indoor and outdoor exposure to allergens and pollutants. As people in modern societies usually spend most of their time indoors, ${ }^{1}$ indoor exposure has been suspected to be an important determinant for the development of asthma and allergic disease.

Several studies have reported an association between damp housing conditions and respiratory symptoms. ${ }^{23}$ However, in studies which have included objective measures of respiratory function the picture has been less clear. In one study no association between bronchial hyperreactivity and dampness was observed, while more respiratory symptoms were reported in children with damp homes at all levels of bronchial reactivity. ${ }^{4}$ Another study found only a weak relation between damp housing conditions and resting lung function while symptoms were increased with dampness. ${ }^{5}$ These observations have raised the question whether the association of reported damp housing conditions and respiratory symptoms may be due to differential reporting bias by parents, aware of the possible detrimental role of their damp homes, than to real increases in respiratory disease.

Damp conditions will cause increased growth of house dust mites ${ }^{6}$ and moulds. An association between exposure to house dust mite in early childhood and the development of allergies and asthma has been found in some, but not all, studies. $^{7-10}$ A recent study identified an association between dampness and mould counts, but there was also evidence of reporting bias. ${ }^{11}$ Mould in the home has been associated with asthma symptoms such as wheeze, ${ }^{45}$ but another study found no difference in mould counts between children with and without wheeze. ${ }^{12}$ Damp conditions may increase allergic sensitisation or lead to respiratory symptoms via ongoing exposure to allergens or other pollutants. ${ }^{13}$

The aim of this study was to assess the relationship between dampness and other risk factors in children with asthma in childhood and the persistence of respiratory symptoms and bronchial hyperreactivity (BHR) in adolescence.

\section{Methods}

STUDY DESIGN

The study was based on a large cross sectional survey of all 4 th grade school children in Munich. ${ }^{14}$ For the purpose of the study this age group was defined as "childhood".

A group of subjects with asthma was identified and followed up three years later ("adolescence"). The appropriate ethics committee had reviewed and accepted both studies.

\section{STUDY POPULATION}

The initial study was conducted from September 1989 to July $1990 .{ }^{14}$ The response rate to the questionnaire was $88 \% ; 5030$ of the participating children were of German nationality. Active asthma was defined as a doctor's
Revised version

Accepted for publication

23 July 1998 
diagnosis of either "asthma", "recurrent asthmatic bronchitis", or "recurrent spastic bronchitis", each with asthma symptoms (breathlessness, asthma attacks, cough) in the last 12 months prior to examination. Children with asthma whose parents had given consent to follow up $(n=234)$ were reinvestigated three years later. A reference group of healthy children was also reinvestigated to yield a cut off point for the definition of BHR for both age groups.

PARENTAL QUESTIONNAIRE

The self administered parental questionnaire of the initial study has been described with the initial study. ${ }^{14} 15$

A child was considered to have more severe asthma if at least one of the following four criteria applied: (1) a diagnosis of asthma $(n=58)$ in contrast to a diagnosis of asthmatic or spastic bronchitis (since in German linguistic usage the former label implies a more serious course of disease); (2) treatment with oral or inhaled steroids ( $\mathrm{n}=12)$; (3) more than 10 asthma attacks in the last 12 months ( $\mathrm{n}=35)$; (4) asthma attacks lasting more than one week ( $\mathrm{n}=$ 47). Respiratory symptoms in the child were considered to be triggered by an allergen if the parents reported contact with animals, grass, or house dust as the major trigger of their child's symptoms. Dampness in the child's home was scored as positive if the parents answered positively the question "Do you have damp spots in your home?".

The questions of the follow up survey were identical to the initial study questionnaire. The questionnaire was administered by trained staff at the Children's Hospital in an interview with a parent of the child at the time of the follow up examination. The definition of persisting asthma symptoms in adolescence was identical to the definition used in the first study - that is, asthma symptoms (breathlessness, asthma attacks, cough) in the last 12 months prior to follow up.

PULMONARY FUNCTION AND COLD AIR CHALLENGE

In the first survey spirometric tests were performed in the schools by trained staff using a mobile spirometer (Pneumoskop II; Jäger, Würzburg, Germany). Cold air challenge was performed using the Respiratory Heat Exchange System (Jäger, Würzburg, Germany). ${ }^{16}$ Spirometric tests and cold air challenge in the second survey were performed according to the same study protocol as in the first survey.

A child was defined as having BHR if the fall in forced expiratory volume in one second after cold air challenge $\left(\mathrm{DFEV}_{1}\right)$ was greater than the 95th percentile of $\mathrm{DFEV}_{1}$ in a reference population. The definition of this healthy reference population (all children without allergies or asthma) has been described elsewhere. ${ }^{16}$ As BHR is expected to change with age, a subgroup was selected randomly from this reference population. The 95th percentile of $\mathrm{DFEV}_{1}$ in this reference subgroup was $9 \%$ in childhood (as in the whole reference group ${ }^{16}$ ). The subgroup was rechallenged in adolescence, giving a 95th percentile of $\mathrm{DFEV}_{1}$ of $14 \%$.
SKIN PRICK TESTS

The sensitivity to six common aeroallergens in the first survey was assessed by skin prick testing on the forearm with a multitest and standardised allergen extracts (house dust mite, grass, birch and hazelnut pollen, cat and dog dander; Stallergènes, France). The cumulative prick score was defined as the sum of the six wheal diameters in $\mathrm{mm}$.

HOUSE DUST MITE MEASUREMENTS

In the follow up study levels of house dust mite antigen were measured in a random subgroup of the study sample. Carefully trained staff vacuumed the mattresses of the child's bed for five minutes. The dust samples were then analysed for house dust mite antigens (Der p 1 and Der f 1) by enzyme linked immunosorbent assay (ELISA).

\section{STATISTICAL ANALYSIS}

Statistical analysis was performed on a personal computer with the statistical software package SAS, version 6.11. Changes between the two surveys were tested for statistical significance by means of Wilcoxon's signed rank test and McNemar's $\chi^{2}$ test. For comparison between independent groups, Wilcoxon's rank sum test was used for continuous data and a standard $\chi^{2}$ test was used for binary data.

In a stepwise backward logistic regression analysis with persisting asthma symptoms in adolescence and BHR in adolescence as outcome variables, the influence of the prognostic factors, as assessed in childhood, on the outcome variables in adolescence was analysed simultaneously. All previously examined prognostic factors (family history, severity of asthma in childhood, degree of BHR in childhood, allergic triggers, prick score, dampness) were included in the models and stepwise exclusion of variables was performed until all remaining prognostic factors had a statistically significant effect. Potential confounding variables were analysed: neither "passive smoking", "pet ownership", nor "socioeconomic status" had any influence on the outcome variables in the univariate or multivariate analyses. Furthermore, if one of these variables was forced into the stepwise regression model the magnitude of the effects of the other variables remained unchanged. When reported medication was analysed, a positive association between BHR and steroid or cromoglycate use was found in the univariate analysis. However, when these variables were forced into the regression model, virtually no change in the effect size of the other variables was seen. The models for both outcome variables were adjusted for sex and for the time interval between the two surveys.

In all analyses a $p$ value of $<0.05$ was considered statistically significant.

\section{Results}

RESPONSE RATES

The initial study had been anonymous and names were replaced by codes. Only children whose parents had consented to follow up and had given their addresses could be identified 
Table 1 Response rates in the follow up study sample $(n=155)$

\begin{tabular}{|c|c|c|c|c|}
\hline & \multicolumn{2}{|c|}{$\begin{array}{l}\text { 1st survey } \\
\text { (childhood) }\end{array}$} & \multicolumn{2}{|c|}{$\begin{array}{l}\text { 2nd survey } \\
\text { (adolescence) }\end{array}$} \\
\hline & No. & $\%$ & No. & $\%$ \\
\hline Parental questionnaire & 155 & 100.0 & 155 & 100.0 \\
\hline Lung function and cold air challenge & 140 & 90.3 & 133 & 85.8 \\
\hline Skin prick test & 133 & 85.8 & - & - \\
\hline Measurement of house dust mite antigen & - & - & 109 & 70.3 \\
\hline
\end{tabular}

for follow up. Forty of the 274 children with active asthma could not be reinvestigated for this reason. Of the remaining 234 children, 155 $(66 \%)$ participated in the follow up study (table 1). Spirometric tests and cold air challenge were performed on $90 \%$ in the first survey and $86 \%$ in the second survey; $80 \%$ completed spirometric tests and cold air challenge in both surveys. Measurement of house dust mite antigen levels in the child's bed was available for $70 \%$. The mean age of the children was 10.2 (range 9-12) years in the first study and $13.3(12-15)$ years in the second survey (table 2).

COMPARISON OF POPULATION CHARACTERISTICS IN CHILDHOOD

The childhood data for the children who participated in the second survey were compared with the data for the children who were lost to follow up (table 2). None of the variables showed a significant difference between the two groups.

PROGNOSTIC FACTORS FOR THE OUTCOME OF ASTHMA, BHR AND RESPIRATORY SYMPTOMS IN ADOLESCENCE

\section{Univariate analysis}

In adolescence 55 of the subjects $(35.5 \%)$ had persisting asthma symptoms; $23(17.3 \%)$ had $\mathrm{BHR}$, a significant decrease compared with the first survey $(27.1 \% \mathrm{BHR}$; $=0.002)$.

Persistence of asthma in adolescence-Table 3 shows the prognostic factors assessed in childhood for the 55 subjects with and the 100 subjects without persisting asthma symptoms in adolescence. $\mathrm{DFEV}_{1}$ in childhood was greater in subjects with persisting asthma symptoms in adolescence than in those without $(\mathrm{p}=0.05)$. Children with more severe asthma $(p=0.001)$ in childhood and children with allergic triggers ( $p$
Table 3 Prognostic factors in childhood: comparison of data for subjects with and without current asthma symptoms in adolescence

\begin{tabular}{|c|c|c|}
\hline Childhood data & $\begin{array}{l}\text { Asthma } \\
\text { symptoms in } \\
\text { adolescence } \\
(n=55)\end{array}$ & $\begin{array}{l}\text { No asthma } \\
\text { symptoms in } \\
\text { adolescence } \\
(n=100)\end{array}$ \\
\hline $\operatorname{DFEV}_{1}(\%)^{\star}$ & $9.2(11.7)$ & $6.1(9.5) 9$ \\
\hline Prick score $(\mathrm{mm})^{\star 1}$ & $13.6(11.2)$ & $11.7(10.3)$ \\
\hline Family history of asthma ${ }^{\star \star}$ & $14 \quad(25.4)$ & $24 \quad(24.0)$ \\
\hline More severe asthma ${ }^{\star \star}$ & $45 \quad(81.8)$ & $55 \quad(55.0) \S$ \\
\hline Allergic trigger ${ }^{\star \star 2}$ & $41 \quad(74.5)$ & $46 \quad(46.0) \S$ \\
\hline Dampness $\star \star 3$ & $10 \quad(20.0)$ & $16 \quad(16.3)$ \\
\hline
\end{tabular}

$\mathrm{DFEV}_{1}=$ difference in forced expiratory volume in one second. ${ }^{\star}$ Mean (SD).

${ }^{\star}$ No. $(\%)$.

${ }^{1}$ Sum of the wheal sizes of the prick tests with six different aeroallergens.

2 Allergic trigger of symptoms according to parental questionnaire.

${ }^{3}$ Dampness in the child's home according to parental questionnaire.

$\$ \mathrm{p}<0.05$ ( $\chi^{2}$ test).

$\Phi \mathrm{p}<0.05$ (Wilcoxon rank sum test).

$=0.009)$ were more likely to have persisting asthma symptoms in adolescence. No significant difference in mite antigen levels between subjects with and without asthma symptoms in adolescence was found. The mean mite antigen level was higher than the proposed threshold value for the development of allergic sensitisation ( $2 \mu \mathrm{g} / \mathrm{g}$ dust) and the provocation of symptoms $(10 \mu \mathrm{g} / \mathrm{g})^{17}$ in both the children with $(14.4 \mu \mathrm{g} / \mathrm{g})$ and without $(10.1 \mu \mathrm{g} / \mathrm{g})$ persisting asthma.

BHR in adolescence - In table 4 a comparison of the prognostic factors for the 23 subjects with and 110 subjects without BHR in adolescence is presented. Reactivity to cold air challenge in childhood was associated with BHR in adolescence $(\mathrm{p}<0.001)$. Subjects with BHR in adolescence had more positive skin prick tests in childhood $(p=0.012)$. Children whose symptoms were triggered by allergen exposure $(p=0.005)$ and children with damp homes $(\mathrm{p}=0.009)$ were more likely to have BHR in adolescence. Subjects with BHR in adolescence had higher mite antigen levels than those without (mean (SD) 16.9 (27.6) $\mu \mathrm{g} / \mathrm{g}$ versus 6.3 (12.4) $\mu \mathrm{g} / \mathrm{g} ; \mathrm{p}=$ $0.012)$.

Table 2 Characteristics of subjects lost to follow up and subjects who participated in the second survey

\begin{tabular}{|c|c|c|c|}
\hline \multirow[b]{2}{*}{ Characteristics } & Lost to follow up & \multicolumn{2}{|l|}{ Follow up } \\
\hline & $\begin{array}{l}\text { Childhood data } \\
(n=119)\end{array}$ & $\begin{array}{l}\text { Childhood data } \\
(n=155)\end{array}$ & $\begin{array}{l}\text { Adolescent data } \\
(n=155)\end{array}$ \\
\hline Age (years) ${ }^{\star}$ & $10.2(0.5)$ & $10.2(0.4)$ & $13.5(0.7)$ \\
\hline Female ${ }^{\star \star}$ & $50 \quad(42.0)$ & $60 \quad(38.7)$ & $60 \quad(38.7)$ \\
\hline Interval between first and second survey (years)^ & - & - & $3.3(0.8)$ \\
\hline Current symptoms ${ }^{\star \star}$ & $119(100.0)$ & $155 \quad(100.0)$ & 55 (35.5)† \\
\hline $\mathrm{BHR}^{\star \star}$ & $24 \quad(23.3)$ & $38 \quad(27.1)$ & $23 \quad(17.3) \dagger$ \\
\hline $\operatorname{DFEV}_{1}(\%)^{\star}$ & $5.4(8.9)$ & $7.2(10.4)$ & $8.7(12.6)$ \\
\hline Prick score $(\mathrm{mm})^{\star 1}$ & $9.9(9.2)$ & $12.4(10.6)$ & - \\
\hline Family history of asthma ${ }^{\star \star}$ & $22(18.5)$ & $38 \quad(24.5)$ & - \\
\hline More severe asthma $a^{\star \star}$ & $79 \quad(66.4)$ & $100 \quad(64.5)$ & - \\
\hline Allergic trigger $\star \star 2$ & $69 \quad(59.0)$ & $87 \quad(56.1)$ & - \\
\hline Dampness $\star \star 3$ & $15 \quad(13.0)$ & $26 \quad(17.6)$ & - \\
\hline
\end{tabular}

$\mathrm{BHR}=$ bronchial hyperreactivity; $\mathrm{DFEV}_{1}=$ difference in forced expiratory volume in one second.

${ }^{\star}$ Mean (SD).

$\star \star$ No. $(\%)$.

${ }^{1}$ Sum of the wheal sizes of the prick tests with six different aeroallergens.

${ }^{2}$ Allergic trigger of symptoms according to parental questionnaire.

${ }^{3}$ Dampness in the child's home according to parental questionnaire.

$t \mathrm{p}<0.05$; comparison of childhood and adolescent data, McNemar's chi-square test 
Table 4 Prognostic factors in childhood: subjects with versus those without bronchial hyperresponsiveness in adolescence

\begin{tabular}{|c|c|c|}
\hline Childhood data & $\begin{array}{l}\text { BHR in } \\
\text { adolescence } \\
(n=23)\end{array}$ & $\begin{array}{l}\text { No BHR in } \\
\text { adolescence } \\
(n=110)\end{array}$ \\
\hline $\mathrm{DFEV}_{1}(\%)^{\star}$ & $14.0(15.4)$ & $6.5(9.0) \Phi$ \\
\hline Prick score $(\mathrm{mm})^{\star 1}$ & $18.9(13.2)$ & $11.3(9.7)$ \\
\hline Family history of asthma ${ }^{\star \star}$ & $5 \quad(21.7)$ & $28 \quad(25.4)$ \\
\hline More severe asthma ${ }^{\star \star}$ & $17 \quad(73.9)$ & $70 \quad(63.6)$ \\
\hline Allergic trigger ${ }^{\star \star 2}$ & $19 \quad(82.6)$ & $56 \quad(50.9) \$$ \\
\hline Dampness $\star \star 3$ & $8 \quad(36.4)$ & $14 \quad(13.3) \S$ \\
\hline
\end{tabular}

$\mathrm{DFEV}_{1}=$ difference in forced expiratory volume in one second. ${ }^{\star}$ Mean (SD).

$\star \star$ No. $(\%)$.

${ }^{1}$ Sum of the wheal sizes of the prick tests with six different aeroallergens.

${ }^{2}$ Allergic trigger of symptoms according to parental questionnaire.

${ }^{3}$ Dampness in the child's home according to parental questionnaire.

$\$ \mathrm{p}<0.05$ ( $\chi^{2}$ test $)$.

$\uparrow \mathrm{p}<0.05$ (Wilcoxon rank sum test).

Dampness and respiratory symptomsReported dampness in the home at the age of 10 was associated with more frequent asthma symptoms during the last 12 months ( $\mathrm{p}=$ $0.025)$, lost school days $(\mathrm{p}=0.01)$, cough with exercise $(p=0.029)$ and at night without a cold $(\mathrm{p}=0.04)$ in childhood (table 5$) ; 14.3 \%$ of the adolescents with dampness in the home at follow up had frequent dyspnoea at night compared with $4.4 \%$ of those without dampness in the home $(p=0.03)$. The same trend was seen with night time wheeze $(14.3 \%$ versus $5.3 \% ; \mathrm{p}=0.06)$. Subjects whose parents reported dampness in the home at the age of 10 also showed a trend towards increased night time dyspnoea $(15.5 \%$ versus $5.7 \%, \mathrm{p}=0.09)$ and night time wheeze $(15.4 \%$ versus $6.6 \%$; $=0.13)$ in adolescence.

Dampness and house dust mite allergen levelsDampness in the homes of adolescents was significantly correlated with higher house dust mite antigen levels $(p=0.05)$. More positive skin prick tests to house dust mite were found

Table 5 Frequency of respiratory symptoms in childhood: comparison of data for subjects with and without dampness in the home in childhood

\begin{tabular}{lll}
\hline Childhood data & $\begin{array}{l}\text { Dampness in } \\
\text { childhood ( } n=26)\end{array}$ & $\begin{array}{l}\text { No dampness in } \\
\text { childhood }(n=122)\end{array}$ \\
\hline Five or more asthma attacks in the last 12 months & $16(61.5 \%)$ & $46(37.7 \%) S$ \\
Three or more weeks of lost school per year & $6(23.1 \%)$ & $8(6.7 \%) \int$ \\
Frequent cough with exercise & $19(79.2 \%)$ & $64(55.2 \%) S$ \\
Frequent cough at night without a cold & $12(46.2 \%)$ & $30(25.9 \%) \$$ \\
\hline
\end{tabular}

\$p $<0.05$ (Fisher's exact test).

Table 6 Results of stepwise backward multivariate logistic regression analysis: adjusted odds ratios (OR) and 95\% confidence intervals (CI) of prognostic factors in relation to outcome of bronchial hyperreactivity (BHR) and of asthma symptoms in adolescence*

\begin{tabular}{|c|c|c|}
\hline \multirow[b]{2}{*}{ Prognostic factors } & \multicolumn{2}{|l|}{$O R(95 \% C I)$} \\
\hline & $\begin{array}{l}\text { Asthma symptoms } \\
\text { in adolescence }\end{array}$ & BHR in adolescence \\
\hline $\mathrm{DFEV}_{1}($ per \%) & - & $1.08(1.03$ to 1.14$)$ \\
\hline Prick score $\left(\right.$ per mm) ${ }^{1}$ & - & - \\
\hline Family history of asthma & - & - \\
\hline More severe asthma & $4.94(1.65$ to 14.76$)$ & - \\
\hline Allergic trigger ${ }^{2}$ & $3.54(1.41$ to 8.92$)$ & $5.47(1.19$ to 25.20$)$ \\
\hline Dampness $^{3}$ & - & 16.14 (3.53 to 73.73 ) \\
\hline
\end{tabular}

${ }^{\star}$ Adjusted for sex and time interval between surveys.

${ }^{1}$ Sum of the wheal sizes of the prick tests with six different aeroallergens.

2 Allergic trigger of symptoms according to parental questionnaire.

${ }^{3}$ Dampness in the child's home according to parental questionnaire.

$\mathrm{DFEV}_{1}=$ difference in forced expiratory volume in one second. in adolescents with dampness at home in childhood $(65 \%$ versus $35 \%$ without dampness; $\mathrm{p}=0.008)$ as well as in adolescence $(55 \%$ versus $35 \%$; $=0.036$ ).

Multivariate analysis (table 6)

Persistence of asthma in adolescence-The risk for persistent symptoms was increased for children with more severe asthma in the first survey (OR $4.94 ; 95 \%$ CI 1.65 to $14.76 ; \mathrm{p}=0.004)$ and if symptoms were triggered by allergens (OR $3.54 ; 95 \%$ CI 1.41 to $8.92 ; \mathrm{p}=0.007$ ).

BHR in adolescence-The risk increased significantly for every percentage change of $\mathrm{DFEV}_{1}$ in childhood (OR 1.08 per \%; 95\% CI 1.03 to $1.14 ; \mathrm{p}=0.004$ ) and was significantly increased if symptoms were triggered by allergens (OR 5.47; 95\% CI 1.19 to $25.20 ; \mathrm{p}=$ 0.029 ) and with dampness (OR 16.14; $95 \%$ CI 3.53 to 73.73 ; $\mathrm{p}<0.001$ ).

If the prognostic factor "allergic trigger" was excluded from the analysis with BHR as outcome variable, the cumulative prick score reached significance and remained in the final model (OR 1.06 per mm; 95\% CI 1.01 to 1.12 ; $\mathrm{p}=0.040)$.

Dampness, house dust mite and BHR-House dust mite antigen measurements were divided into quartiles and included in the stepwise backward logistic regression analysis. The risk of having BHR doubled with each quartile of house dust mite antigen levels (OR 2.30; 95\% CI 1.03 to $5.12 ; p=0.042)$. An "allergic trigger of symptoms" (OR 5.71; 95\% CI 1.06 to 30.74; p = 0.042) and "dampness" (OR 5.77; $95 \%$ CI 1.17 to $28.44 ; \mathrm{p}=0.031$ ) remained significant prognostic factors for BHR in adolescence despite the inclusion of mite antigen levels as an independent risk factor in the multivariate model.

\section{Discussion}

PERSISTENCE OF ASTHMA AND BHR IN

ADOLESCENCE

More severe asthma, allergic triggers, and increased BHR in childhood were found to be risk factors for persistent asthma and BHR. This is in agreement with an Australian cohort study of school children which found BHR at the age of $8-10$ years to be associated with atopy and increased asthma symptoms during a four year follow up. ${ }^{18} \mathrm{~A}$ follow up of asthmatic children (mean age 10 years) referred to a paediatric pulmonology department into adulthood (mean age 24 years) identified the severity of asthma and BHR in childhood as risk factors for respiratory symptoms in adulthood. ${ }^{19}$ The initial questionnaire in our study had been self administered, while at follow up it was administered by staff. This may have influenced the reported prevalence of symptoms and exposure in the two phases of the study, but it appears unlikely that this difference could explain the observed association of dampness, measured house dust mite antigen, and BHR with symptoms in adolescence.

If hyperreactivity is used as an epidemiological tool in unselected populations or in patients with only a history of asthma symptoms, sensitivity is much lower than in clinical studies 
investigating patients with acute asthma. ${ }^{16} 20$ Even in asymptomatic children, BHR may be associated with subsequent development of asthma. ${ }^{21}$ Bronchial reactivity in childhood was greater in children who progressed to persisting asthma symptoms. The risk of having BHR in adolescence was increased with the degree of reactivity in childhood, with allergic triggers for respiratory symptoms, and with damp homes. If the prognostic factor "allergic trigger" was excluded from the analysis (as a substitute variable for atopy), the cumulative prick score remained a significant predictor in the final model. A follow up study of a birth cohort of children in New Zealand included repeated methacholine tests from age nine to $15 .^{22}$ Similar to our results, bronchial responsiveness at the age of nine was found to be associated with BHR at the age of 15 , and positive skin prick tests were related to the tendency to retain BHR into adolescence. A study following asthmatic children into adulthood similarly found that the skin prick test score and the level of airway reactivity in childhood was related to BHR in adulthood. ${ }^{1923} 24$

The 95th percentile of $\mathrm{DFEV}_{1}$ in the control group was $14 \%$ in adolescence compared with $9 \%$ at age 10 , which is in contrast to the decrease in bronchial reactivity to pharmacological provocations with age. ${ }^{25}$ This decrease has been attributed to younger children receiving relatively larger doses of the inhaled substance, ${ }^{26}$ which may not be relevant for the cold air hyperventilation challenge where the thermal load is adapted to actual lung size. A variation in the cut off point (between $9 \%$ and $15 \%$ ) for the definition of BHR had no influence on the significant variables remaining in the final logistic regression model for BHR in adolescence. The specificity of cold air challenge in both parts of the study was, by definition, $95 \%$. Using the resulting cut off point, the frequency of positive tests in children with asthma and symptoms during the last 12 months was $27 \%$ in the first study and $28 \%$ in the follow up - that is, the sensitivity of cold air challenge to detect children with active asthma was unchanged. The decreasing frequency of asthma symptoms from childhood to adolescence which we found is in agreement with other data ${ }^{27}$ and was parallelled by a decrease in the prevalence of BHR.

\section{DAMPNESS}

Dampness in the home in childhood was associated with respiratory symptoms at this age and with night time respiratory symptoms and BHR in adolescence. The question used to define damp homes asked whether there was water related damage in the home. This question has also been used in other studies, ${ }^{28}$ where a physician diagnosis of asthma was associated with household water damage. A number of other paediatric studies found dampness to be associated with respiratory symptoms but not with asthma. ${ }^{29-31}$ Our study differs from these investigations in that it assessed the persistence of established asthma rather than the development of new cases of asthma or respiratory symptoms in unselected populations of children.

Few studies analysing the relation between dampness at home and respiratory health in children have included objective measurements such as lung function tests or bronchial provocation. One report found no association of dampness with baseline lung function in children. ${ }^{32}$ Increased wheeze in children with dampness in the home but no association with BHR (as measured by a free running test) was found in another study. ${ }^{4}$ A survey of school children found that damp stains and moulds in the home were associated with chronic cough and small but significant impairments of lung function. ${ }^{33}$ Analysis of dampness in the homes of children from the Six Cities study in the USA resulted in a consistent association with respiratory symptoms and a small reduction in lung function. ${ }^{5}$

The frequency of damp homes seems to vary considerably from $17 \%$ in our study (dampness in both childhood and adolescence was reported in $13.5 \%$ ) to $37 \%$ in a subtropical climate $^{34}$ and $59 \%$ reported in Ontario. ${ }^{11}$ No objective measurement of dampness was performed in our study, which would have strengthened the observed associations. A number of investigators have sought to define dampness better either by inspection or measurements of temperature, humidity, mould counts, and house dust mite allergen measurements. However, when visual inspection was used to define dampness, the same association with respiratory symptoms was seen. ${ }^{35-37}$ We found that dampness was significantly correlated with the amount of house dust mite antigen in the dust vacuumed from the children's mattresses. This is in agreement with a number of other studies reporting increased mite exposure in damp homes from different climatic regions. ${ }^{13} 38-40$

Allergy to house dust mite or mould spores in asthmatic children and increased exposure to these allergens in damp homes has been proposed as the likely biological mechanism linking dampness and respiratory symptoms. ${ }^{13} 35$ In our study the level of mite exposure was directly related to the level of BHR in adolescence. In contrast to our results, a study using exercise testing in younger school children sensitised to house dust mite found no relationship between the level of mite exposure and bronchial reactivity. ${ }^{41}$ However, the children studied were much younger (eight years) and may be comparable to the children in our initial study where we found no association between dampness and bronchial reactivity. Interestingly, the association of dampness with BHR was not found for adolescents whose parents reported dampness at the time of follow up but not during the initial study (data not shown). This might indicate that long term exposure is needed for the effect of dampness on BHR.

Dampness remained a significant risk factor for $\mathrm{BHR}$ in a stratified logistic regression model at each level of house dust mite antigen, indicating that there may be an additional risk factor independent of mite exposure associated 
with dampness. Mould exposure has been proposed as such an alternative mechanism. Data relating mould exposure to dampness are more equivocal than those for mites. ${ }^{12}$ Other studies found no significant differences in fungal concentrations in homes with and without reported dampness. ${ }^{42}$ Whether the prognosis of childhood asthma can be influenced by reducing dampness in the home can only be determined by prospective interventional studies.

1 Moschandreas DJ. Exposure to pollutants and daily time budgets of people. Bull NY Acad Med 1981;57:845-59.

2 Waegemaekers $M$, van Wageningen $\mathrm{N}$, Brunekreef $\mathrm{B}$, et al. Respiratory symptoms in damp houses. Allergy 1989;44: $192-8$

3 Andrea S, Axelson O, Björksten B, et al. Symptoms of bronchial hyperreactivity and asthma in relation to environmental factors. Arch Dis Child 1988;63:474-8.

tal factors. Arch Dis Child 1988;63:474-8.
4 Strachan DP. Damp housing and childhood asthma: validation of reporting of symptoms. BMF 1988;297:1223-6.

5 Brunekreef B, Dockery DW, Speizer FE, et al. Home dampness and respiratory morbidity in children. Am Rev Respir ness and respiratory
Dis $1989 ; 140: 1363-7$

6 Hart BJ, Whitehead L. Ecology of house dust mites in Oxfordshire. Clin Exp Allergy 1990;20:203-9.

7 Sears MR, Herbison GP, Holdaway MD, et al. The relative risks of sensitivity to grass pollen, house dust mite, and cat dander in the development of childhood asthma. Clin Allergy 1989;19:419-24

8 Sporik N, Holgate ST, Platts-Mills TAE, et al. Exposure to house dust mite allergen and the development of asthma in childhood. N Engl 7 Med 1990;323:502-7.

9 Burr ML, Miskelly FG, Butland BK, et al. Environmental factors and symptoms in infants at high risk of allergy. $\mathcal{F}$ Epidemiol Community Health 1989;43:125-32.

10 Strachan DP, Paine KM, Butland BK, et al. House dust mite allergy, mite allergen exposure and childhood asthma: a allergy, mite allergen exposure and childhood asthma: a

11 Dopulation-based case-control study. Thorax 1993;48:426-7. health: validity and determinants of reported home damphealth: validity and determinants of reported hom

12 Strachan D, Flannigan B, McCabe EM, et al. Quantification of airborne moulds in the homes of children with and without wheeze. Thorax 1990;45:382-7.

13 Strachan DP. Moulds, mites and childhood asthma. Clin Exp Allergy 1993;23:799-801.

14 von Mutius E, Martinez F, Fritzsch Ch, et al. Prevalence of asthma and atopy in two areas of East and West Germany. Am F Respir Crit Care Med 1994;149:358-64.

15 American Thoracic Society Committee on Diagnostic Standard for Nontuberculous Diseases. Definitions and classification of chronic bronchitis, asthma and pulmonary emphysema. Am Rev Respir Dis 1962;85:762.

16 Nicolai T, von Mutius E, Wjst M, et al. Reactivity to cold air hyperventilation in normal and asthmatic children in a survey of 5697 school children in Southern Bavaria. Am Rev Respir Dis 1993;147:565-72.

17 Platts-Mills T, Wayne RT, Aalberse RC, et al. Dust mite allergens and asthma. F Allergy Clin Immunol 1992;89. allergens

18 Peat JK, Salome CM, Sedgwick CS, et al. A prospective study of bronchial hyperresponsiveness and respiratory symptoms in a population of Australian school children. Clin Exp Allergy 1989;19:299-306.

19 Roorda RJ, Gerritsen J, van Aalderen WMC, et al. Risk factors for the persistence of respiratory symptoms in childhood asthma. Am Rev Respir Dis 1993;148:1490-5.

20 Sears MR, Jones DT, Holdaway MD, et al. Prevalence of bronchial reactivity to inhaled methacholine in New Zealand children. Thorax 1986;41:283-9.
21 Jones A. Asymptomatic bronchial hyperreactivity and the development of asthma and other respiratory tract illnesses in children. Thorax 1994:49:757-61.

22 Burrows B, Sears MR, Flannery EM, et al. Relation of the course of bronchial responsiveness from age 9 to age 15 to allergy. Am f Respir Crit Care Med 1995;152:1302-8.

23 Roorda RJ, Gerritsen J, van Aalderen WMC, et al. Skin reactivity and eosinophil count in relation to the outcome of childhood asthma. Eur Respir f 1993;6:509-16.

24 Roorda RJ, Gerritsen J, van Aalderen WMC, et al. Follow up of asthma from childhood to adulthood: influence of potential childhood risk factors on the outcome of pulmopotential childhood risk factors on the outcome of pulmoAllergy Clin Immunol 1994;93:575-84.

25 Forastiere F, Corbo GM, Dell'Orco V, et al. A longitudinal evaluation of bronchial responsiveness to methacholine in children: role of baseline lung function, gender, and change in atopic status. Am f Respir Crit Care Med 1996;153:1098104.

26 Le Souef PN, Sears MR, Sherrill D. The effect of size and age of subject on airway responsiveness in children. $A m \mathcal{F}$ Respir Crit Care Med 1995;152:576-9.

27 Balfour-Lynn L. Childhood asthma and puberty. Arch Dis Child 1985;60:231-5.

28 Maier WC, Arrighi HM, Morray B, et al. Indoor risk factors for asthma and wheezing among Seattle school children. Environ Health Perspect 1997;105:208-14.

29 Gustafsson D, Andersson K, Fagerlund I, et al. Significance of indoor environment for the development of allergic symptoms in children followed up to 18 months of age. Allergy 1996;51:789-95.

30 Kelly YJ, Brabin BJ, Milligan PJ, et al. Clinical significance of cough and wheeze in the diagnosis of asthma. Arch Dis Child 1996;75:489-93.

31 Yang CY, Chiu JF, Chiu HF, et al. Damp housing conditions and respiratory symptoms in primary school children. Pediatr Pulmonol 1997;24:73-7.

32 Dijkstra L, Houthuijs D, Brunekreef B, et al. Respiratory health effects of the indoor environment in a population of Dutch children. Am Rev Respir Dis 1990;142:1172-8.

33 Cuijpers CE, Swaen GM, Wesseling G, et al. Adverse effects of the indoor environment on respiratory health in primary school children. Environ Res 1995;68:11-23.

$34 \mathrm{Li} \mathrm{CS}, \mathrm{Hsu} \mathrm{LY}$. Airborne fungus allergen in association with residential characteristics in atopic and control children in a subtropical region. Arch Environ Health 1997;52:72-9.

35 Verhoeff AP, van Strien RT, van Wijnen JH, et al. Damp housing and childhood respiratory symptoms: the role of sensitization to dust mites and molds. Am $\mathcal{F}$ Epidemiol 1995;141:103-10

36 Brunekreef B. Damp housing and adult respiratory symptoms. Allergy 1992;47:498-502.

37 Mohamed N, Ng'ang'a L, Odhiambo J, et al. Home environment and asthma in Kenyan schoolchildren: a casecontrol study. Thorax 1995;50:74-8.

38 Placido JL, Qeusta C, Delgado L, et al. Indoor mite allergens in patients with respiratory allergy living in Portugal. in patients with respirat

39 Munir AK, Bjorksten B, Einarsson R, et al. Mite allergens in relation to home conditions and sensitization of asthmatic children from three climatic regions. Allergy 1995;50:5564 .

40 Van Strien RT, Verhoeff AP, Brunekreef B, et al. Mite antigen in house dust: relationship with different housing characteristics in the Netherlands. Clin Exp Allergy 1994;24: 843-53.

41 Frischer TH, Kuehr J, Meinert R, et al. Relationship between exposure to dust mite allergen and bronchial response to exercise in schoolchildren sensitized to dust mites. Pediatr Pulmonol 1993;16:13-8.

42 Verhoeff AP, van Wijnen JH, van Reenen Hoekstra ES, et al. Fungal propagules in house dust. Relation with residential characteristics and respiratory symptoms. Allergy 1994;49: $540-7.43$ 